\title{
A multi-scale investigation of the dynamics of co-dissolution and precipitation at water-rock interface
}

\author{
HANG DenG $^{1}$, SeRgi Molins ${ }^{2}$, JenNA POONOOSAMY ${ }^{3}$, \\ MARTINA KLINKENBERG ${ }^{4}$ \\ ${ }^{1}$ Lawrence Berkeley National Laboratory, Berkeley, CA, \\ USA, 94720, hangdeng@lbl.gov \\ ${ }^{2}$ Lawrence Berkeley National Laboratory, Berkeley, CA, \\ USA, 94720, smolins@1bl.gov \\ ${ }^{3}$ Institute of Energy and Climate Research (IEK-6): Nuclear \\ Waste Management and Reactor Safety, 8 \\ Forschungszentrum Jülich GmbH, 52425 Jülich, \\ Germany, j.poonoosamy@fz-juelich.de \\ ${ }^{4}$ Institute of Energy and Climate Research (IEK-6): Nuclear \\ Waste Management and Reactor Safety, 8 \\ Forschungszentrum Jülich GmbH, 52425 Jülich, \\ Germany, m.klinkenberg@fz-juelich.de
}

Water-rock interface evolves as a result of mineral dissolution and precipitation. In many cases, dissolution of the substrate mineral can create supersaturation conditions with respect to a new mineral phase. The dynamics of the codissolution and precipitation processes include complex feedback: the dissolution of the primary mineral is required for subsequent precipitation, whereas the dissolution reaction may be suppressed by the precipitation of the secondary mineral. Previous column experiments of celestine dissolution and barite precipitaiton have shown that the thickness of the coating layer is largely controlled by the precipitation rate that was varied via the supply of $\mathrm{Ba}^{2+}$ in the influent [1]. Given the same flow rate, with higher precipitation rate, the coating layer developed at both the upstream and downstream; while for a lower precipitation rate, the barite precipitation is localized at the upstream, where celestine is almost depeleted.

In this study, using numerical simulations, we investigate the interactions between reaction rate, pore flow, and diffusion through the coating layer, and their impacts on the dynamic evolution of the coating layer. In addition to transition state theory type of rate laws, we also describe the precipitation process using heterogeneous nucleation rate that is dependent on the saturation index. Another novel aspect of our study is to examine how different precipitation mechanisms affect the texture and transport properties of the coating layer.

[1] Poonoosamy, J. et al, Effects of solution supersaturation on barite precipitation in porous media and consequences on permeability: experiments and modelling. Geochimica et Cosmochimica Acta, 2020, 270, pp 43-60. 